\title{
Does innovation need reanalysis?
}

\author{
Hendrik De Smet \\ University of Leuven / Research Foundation Flanders
}

\begin{abstract}
Syntactic reanalysis has been claimed to be the only mechanism capable of explaining syntactic change. However, the concept of syntactic reanalysis is flawed. It insufficiently accommodates gradience in synchronic grammar and in language change, and depends too heavily on ambiguity as a cause of change. Alternative mechanisms exist to account for innovation that do not suffer from these problems. At the same time, the problem of explaining syntactic innovations is partly tied to models of language that overstate the role of syntax. Part of the problem therefore disappears under different theoretical starting assumptions.
\end{abstract}

\section{Introduction}

It is generally assumed that language change is not a goal in itself but happens as a side-effect of language users' pursuit of other goals (Keller 1990; Joseph 1992; Berg 1998; Haspelmath 1999; Fischer 2000; Croft 2000). One implication of this is that a specific innovation is likely only to the extent that it can somehow arise from how language is routinely used, in the widest possible sense - including how language is acquired, how it is mentally represented, how utterances are processed, or how they are produced and interpreted. Explanations of change thus have to account (among other things) for how innovations arise out of the mechanically implemented strategies of language use. ${ }^{1}$

Evidently, this idea is largely vacuous unless it comes with further specifications as to how language actually works. Inevitably, however, different models of language disagree on this and, as a result, predict different types of change and authorize different kinds of diachronic explanations. It is one such conflict - concerning the viability of certain diachronic explanations within a particular model of language - that is the focus of the present paper.

Specifically, this paper addresses the question whether and how the notion of syntactic reanalysis can be integrated in a usage-based approach to language and language change (as formulated in Langacker 1987; Barlow \& Kemmer 2000; Croft 2001; Croft \& Cruse 2004; Goldberg 2006; Bybee 2010). Reanalysis, as traditionally conceived, is the privileged mechanism to account for syntactic

\footnotetext{
${ }^{1}$ Another aspect of change to account for is how innovations are propagated. Typically explanations of this aspect of change make reference to social needs (Croft 2000) or the communicative needs of clarity and efficiency (Haspelmath 1999). Explanations of this type are also user-based, but focus on speaker motivations (at various levels of linguistic awareness) rather than on the workings of the linguistic system per se.
} 
change. Its explanatory value has been called into question, however, both on empirical and on theoretical grounds (Haspelmath 1998; Fischer 2007; De Smet 2009; Bybee 2010). The arguments advanced against reanalysis have in common that they build on the central tenets of usage-based approaches, relating to usage-based views on syntactic categorization and the mental representation of syntactic structures. Accordingly, in this paper, the various arguments are brought together and evaluated to show that if the central claims of usage-based models are taken seriously the traditional concept of reanalysis is problematic. Importantly, this critique is as much a challenge to usage-based models of language change as it is to the traditional notion of reanalysis. After all, such models face a serious problem with the facts of language change if they cannot come up with workable alternatives to account for innovation.

The rest of this paper is organized as follows. Since the term reanalysis has been variously interpreted, Section 1 below starts out by outlining the specific view on reanalysis taken issue with here. Section 2 then describes the problems this view faces. These have to do with the nature of reanalysis, especially its abruptness, the role of ambiguity, and the ability of reanalysis to create genuinely new syntactic representations. If reanalysis is inadequate to explain the emergence of novel structures, as will be argued, the question arises what can come in its place. In response, Section 4 on the one hand discusses some alternative ways in which innovative syntactic structures can come into existence, and on the other argues that some problems associated with reanalysis disappear under an altered view of syntactic structure. Section 5 concludes the discussion by assessing the value of reanalysis as a theoretical concept.

\section{Reanalysis}

The view of reanalysis specifically at issue here can be found in a good number of treatments on the topic, including Andersen (1973, 2001), Langacker (1977), Timberlake (1977), Lightfoot (1979), Anttila (1989), Kroch (1989), Harris \& Campbell (1995), Newmeyer (1998), Harris (2003), Hopper \& Traugott (2003), Van Gelderen (2004), Roberts (2007), and others.

Needless to say, not all of these authors subscribe to exactly the same view or use the same terminology, but for present purposes the commonalities are greater than the differences. Most fundamentally, all of the authors listed above share the conviction that there exists such a thing as abstract syntactic representation, be it as the outcome of innate principles that determine the architecture of a grammar, or as the product of generalizations abstracted from linguistic experience. This type of abstract knowledge, whatever its precise nature or origin, infuses a measure of predictability in language use. For instance, in English, a form that enters the empty slot in my _-est friend is expected to also enter the empty slot in $a$ _friend. Views diverge on just how much predictability syntax brings to language, as well as on the extent to which abstract representations exist in their own right, independently of linguistic function. These issues are returned to in the following sections. For now, however, 
discussion is based on the shared assumption that syntactic structure exists and can be described as an autonomous entity.

Against this background, all the above authors accept that syntactic reanalysis is a mechanism ${ }^{2}$ of change that assigns a new underlying structure to a surface sequence without overtly modifying that sequence. This is captured, for instance, in Langacker's often-quoted definition of the term:

I will define "reanalysis" as a change in the structure of an expression or class of expressions that does not involve any immediate or intrinsic modification of its surface manifestation. Reanalysis may lead to changes at the surface level [...] but these surface changes can be viewed as the natural and expected result of functionally prior modifications in rules and underlying representations. (Langacker 1977: 58)

As is also apparent from Langacker's definition, reanalysis - while itself invisible - may cause surface changes. In fact, the appearance of manifestly new surface patterns is the only evidence that reanalysis has taken place. As Hopper \& Traugott put it:

The reanalysis itself is covert until some recognizable modification in the forms reveals it. (Hopper \& Traugott 2003: 50)

The set of surface changes that follow from reanalysis are usually said to constitute the actualization phase of change. Note that reanalysis thus precedes and causes actualization. This is implicit in the quotation from Langacker (1977) above, and explicit in the following quotation from Harris, who, writing about actualization, states:

there would be no reason for these surface changes, extensions, to take place unless reanalysis had already occurred (Harris 2003: 536)

Typically, reanalysis and actualization are attributed two more properties. First, reanalysis is abrupt, at least in a qualitative sense. ${ }^{3}$ That is, there is a shift between two representations that are radically distinct, with no in-between alternatives. This idea is prominent in early treatments of re-

\footnotetext{
${ }^{2}$ The term mechanism is used here to refer a particular constellation of factors causing one state to change into another. It therefore collapses the distinction between motivation and mechanism drawn by Traugott \& Trousdale (2010), where mechanism is restricted to describing a type of historical relation between one state and another, without specifying what motivates the transition between them.

${ }^{3}$ Temporal abruptness can probably be regarded as a non-issue, since even if they are radically distinct, different underlying analyses can continue to exist side by side for some time, within a speaker community as a whole and even within the same speaker (Hopper \& Traugott 2003).
} 
analysis, where it is sometimes whole grammars that are said to change. For example, of the stage between reanalysis and actualization, Anttila writes:

the two grammars are the same for practical needs, although they may be drastically different in structure (Anttila 1989: 197)

But the view is echoed in more recent interpretations. For example:

When an innovated form B enters the grammar alongside of an older form A, it does so abruptly: an Ewe language user either does or does not use bé as a complementizer (Hopper \& Traugott 2003: 46)

It is likely that the abruptness of reanalysis relates to the theory of syntactic structure used to describe it. Harris, for example, is relatively clear about what she means by underlying structure, and the kind of structural relations she singles out seem to leave little to no room to intermediate steps or gradual transitions:

Reanalysis is a mechanism which changes the underlying structure of a syntactic pattern and which does not involve any modification of its surface manifestation. We understand underlying structure in this sense to include at least (i) constituency, (ii) hierarchical structure, (iii) category labels, and (iv) grammatical relations. (Harris 2003: 532)

In contrast to reanalysis, actualization is commonly seen as gradual, in the sense that it potentially involves multiple small surface changes that do not take place simultaneously. For instance, Timberlake characterizes actualization as "the gradual mapping out of the consequences of [...] reanalysis [italics added]" (1977: 141), and further on writes:

It seems that typically the actualization of a reanalysis occurs earlier in some contexts, or for some elements, than others. (Timberlake 1977: 141)

Second, reanalysis takes place through ambiguity. It is because some surface sequences allow two alternative analyses that the shift from one analysis to the other can take place. The shift may or may not happen in the process of language acquisition; and additional deeper factors may be involved, such as the maintenance of a balance between transparency and code simplicity (Langacker 1977), the avoidance of opaque grammars (Lightfoot 1979), or the application of linguistic universals (Andersen 1973; Anttila 1989). Regardless of such various additions, however, ambiguity remains the condition crucial for change to take place. This is clear from the following quotations: 
Reanalysis is made possible by the potentially ambiguous character of surface output (Timberlake 1977: 168)

Everybody has to abduce his own grammar from the output of other grammars; in this situation ambiguities can be newly resolved. (Anttila 1989: 197)

reanalysis depends upon the possibility of multiple analysis (Harris 2003: 532)

In every instance of reanalysis we can posit that it is the result of abduction. In some contexts two interpretations were possible, that is, there was at least the potential for ambiguity (also called "opacity") that allowed for the structure to continue to be analyzed as before, and for a new analysis to be innovated and then to coexist with the earlier analysis. (Hopper \& Traugott 2003: 52)

Many instances of language change can be interpreted in terms of reanalysis as described here. Consider about, which developed from a preposition to an approximative marker (cf. Plank 2004). In (1a) about is a preposition meaning 'around'. In (1b), it is used metaphorically, with an approximative meaning. Its syntactic status is obscured by its use in an apposition, leaving it ambiguous between a preposition and an approximative marker. In (1c-d), it is without doubt an approximative marker, since it introduces a clausal argument (1c) or follows another preposition (1d).

(1) a. Seo firmament tyrnð symle onbutan us (c1000, OED)

'The firmament turns ever around us'

b. Man slóh ðær mycel wæl, abutan feower hund manna, oððe fife. (1055, OED)

'A major force was slain there, about four or five hundred men.'

c. WHANNE Athelstan was dede his broper Edmond bygan to regne in his twentipe zere of age, and regnede aboute an sevene zere (a1387, PPCME2)

'when Athelstan was dead his brother Edmund began to reign at the age of twenty, and reigned about seven years'

d. he confermed pe worschippynge of holy ymages in a counsaile pat was i-made at Rome of aboute a powsand bisshoppes (a1387, PPCME2)

'he [pope Gregory III] approved of worshiping holy images in a council of about a thousand bishops that was held at Rome'

On the view outlined here, it is because contexts like (1b) are ambiguous that about can be reanalyzed from being the head of a prepositional phrase $\left(\left[\text { abutan }_{\text {PREP }}\left[[\text { feower hund }]_{\text {NUM }} \text { manna }\right]_{N P}\right]_{P P}\right)$ to being a 
modifier of a numeral within a noun phrase ([[[abuton $]_{\mathrm{APP}}$ feower hund $]_{\mathrm{NUM}}$ manna $\left.]_{\mathrm{NP}}\right)$. When reanalysis takes place, the shift is abrupt, since no intermediate interpretation is logically available. The shift does not visibly alter the behaviour of the linguistic item. Only later is the syntactic change effected by reanalysis revealed as new behaviour appears that is irreconcilable with the item's original syntactic status, as seen in contexts like (1c-d).

\section{Problems}

The view on reanalysis laid out in the previous section is problematic, partly on empirical and partly on theoretical grounds. To show this, the following discussion focuses on two problem areas, one relating to the idea that reanalysis is abrupt, the other having to do with the assumed role of ambiguity.

Two remarks are in place at the outset. First, the problems discussed here pertain to how certain changes are accounted for. As such, all they imply is that reanalysis, as understood above, may not adequately model what language users do when they unintentionally change the language. The critique formulated does not amount to a refutation of the changes themselves, which remain to be explained. The question of alternative explanations is returned to in Section 4 below. Second, the term reanalysis is sometimes used without the additional assumptions of abruptness or causation through ambiguity. While this use of the term is less problematic, it is essentially descriptive - classing together changes that are seen to affect the underlying relations within a syntagm - and has no explanatory power in its own right.

\subsection{Abruptness}

One problem area in the view on reanalysis outlined above is the assumption that a surface form switches abruptly from one syntactic representation to another. This idea has been criticized from a number of perspectives.

Probably the best-known challenge to abruptness has come from research in grammaticalization. The challenge is partly framed against the background of a broader discussion in the grammaticalization literature on whether grammaticalization is distinct from traditionally recognized types of language change, particularly reanalysis. Three different positions have been defended, which differ in either seeing grammaticalization as a type of reanalysis (Meillet 1912; Roberts 2007), reanalysis as one aspect of grammaticalization (Heine, Claudi \& Hünnemeyer 1991; Hopper \& Traugott 2003), or reanalysis and grammaticalization as fully distinct and independent phenomena (Haspelmath 1998). For the most part, the whole discussion is about the usefulness of grammaticalization as a theoretical construct (Campbell 2001; Joseph 2004), but because it also deals with the nature of (a subset of) structural changes, it is relevant here as well. Specifically, it has been argued that grammaticalization implements structural change gradually rather than abruptly (Haspelmath 1998; Bybee 2006). If so, 
this implies that many purported cases of reanalysis may violate the abruptness associated with reanalysis.

The gradualness of grammaticalization manifests itself under different forms. For word class changes, Haspelmath (1998) argues that transitions from one word class to another tend to be stepwise, with an item assuming the formal properties of its new word class one by one. ${ }^{4}$ His most elaborate example comes from Kortmann \& König's (1992) study of prepositions developing out of verbs in European languages. The study demonstrates that some of those prepositions (such as English during or pending) show many prepositional properties whereas others (such as English preceding or facing) show few. ${ }^{5}$ From this, Haspelmath goes on to state:

In discussions of syntactic change, thinking in discrete terms where the phenomena are gradient means that clear instances of grammaticalization are erroneously attributed to reanalysis because grossly oversimplified tree diagrams [...] do not reflect the gradualness of the change. (Haspelmath 1998: 330)

It may be countered here that Haspelmath simply confuses reanalysis and actualization, attributing the gradualness of the latter to the former. This is an interpretation he anticipates and argues against, albeit on largely theoretical grounds (Haspelmath 1998: 340-134). Clearly, once gradient class membership is recognized as a synchronic phenomenon, it will be hard to find compelling reasons for dismissing it in diachrony (cf. Traugott \& Trousdale 2010). But even regardless of this theoretical argument, Haspelmath strikes a sensitive chord, since the assumed abruptness of reanalysis does leave unexplained the gradualness of actualization. That is, if reanalysis is abrupt, then why is actualization gradual? Does it make sense to speak of an abrupt (and therefore, by definition, completed) structural change when the formal evidence for it is still underway and may in fact never reach the stage of being fully consistent?

In other cases, gradualness in grammaticalization has been linked to the gradient character of frequency effects. Particularly at issue are changes said to involve rebracketing through fusion, such as the often-cited changes that gave rise to the English semi-modals, gonna, gotta, hafta, wanna and the like. The formal erosion here is generally recognized to be gradual. For want to, for instance, Krug

\footnotetext{
${ }^{4}$ To be sure, Haspelmath's (1998) argument against reanalysis in grammaticalization is more complex. It also proposes that grammaticalization, unlike reanalysis, is unidirectional and involves loss of autonomy. Further, the role of structural change in grammaticalization is downplayed by denying the occurrence of structural change in many instances of grammaticalization.

${ }^{5}$ Haspelmath's choice of example is somewhat unfortunate because Kortmann \& König's (1992) study presents little evidence that deverbal prepositions actually move along the verb-to-preposition gradient over time. This is not too problematic, however, since there are other clearer examples of items that gradually adopt new formal behaviour and, with it, a new structural status - see, for example, the development of adnumeral markers discussed in Plank (2004) and the specific example of English about, discussed in Section 2 above.
} 
(2000: 152) proposes the following realizations, stretching gradualness about as far as basic phonetic notation allows: ['wpnt, thu:], ['wpnt, to], ['wpnt $\sigma$ ], ['wpntə], ['wpnə], ['wənə], [won] and (for American English) [wã]. Formal fusion in the semi-modals is also commonly believed to accompany an underlying syntactic shift, with rebracketing of a sequence of main verb and infinitival to to a single auxiliary-like operator. The question now is whether the syntactic transition is likewise gradual. It can be, if the crucial development is understood in terms of a frequency-driven decrease in compositionality. Thus, Bybee \& McClelland state:

Repeated exposure to a particular phonological pattern (be it one we classically call a morpheme, a word, or even a sequence of words) increases speed and fluency of processing of the pattern. [...] As this process is repeated, any tendency toward compositionality within the pattern is gradually reduced, leading to words and word sequences losing their compositionality if they are of high absolute or relative frequency. (Bybee \& McClelland 2005: 396)

On this view, there is no cut-off point at which want to ceases in the eyes of the language user to consist of two separate elements and is fused into one (see also Bybee 2004, 2006, 2010). The evidence from grammaticalization primarily demonstrates the relation between frequency and gradual formal fusion (Krug 2000). That the loss of underlying compositionality is also a gradient phenomenon is mainly supported by research in other domains, notably morphology (Hay \& Baayen 2005). However, even if the best evidence is indirect, it still casts doubt on the logical necessity of (invariably) discrete constituent structures in syntax, as well as on the value of fused forms as evidence of rebracketing.

Both within and beyond the domain of grammaticalization, there is another reason to question the abruptness of reanalysis. That is the existence of hybrids. Hybrids manifest conflicting behavioural features, providing evidence that some surface forms instantiate different underlying structures at the same time. Hybridization is commonly found in actualization processes, indicating that instances of a reanalyzed item need not resort either under its old or its new analysis. Instead, the old and new analyses can simultaneously influence the item's behaviour (De Smet 2012a). The idea that a form instantiates either one structure or another is thereby contradicted.

For example, in binominal phrases the first noun may develop into a quantifier and lose its nominal status (Brems 2003; Traugott 2008; Verveckken 2012). This can be shown for English (a) lot (of), which in (2a) is used in one of its original senses ('a set of articles to be sold in batch') but in (2b) functions as a quantifier indicating a large amount of something. Syntactically, lot in (2a) triggers singular agreement on the verb and so can be analyzed as the head noun of the binominal phrase a lot of goods, but in (2b) it is parchments that determines agreement and must be the head noun in a lot of parchments, suggesting that (a) lot (of) must be a quantifier (Brems 2003).

(2) a. a lot of goods is to be fitted out for auction (1853, COHA) 
b. a lot of parchments about the chair / Are handed to witnesses then and there (1859, COHA)

However, the syntactic division between quantifier and head noun is not watertight. If lot is part of a quantifier it should not combine with adjectives and if it is a noun it should not relinquish its head status, yet in (3) it behaves as a noun in selecting a modifying adjective ( $a w f u l$ ) but as a quantifier in being transparent to agreement.

an awful lot of people are on medication who don't need it. (1993, COHA)

The same ambivalent situation is attested in other European languages, as illustrated in (4) for French, Dutch and Spanish. Especially in French the phenomenon is very common and the set of modifying adjectives quite open-ended (perhaps because of the four languages, French is the least systematic in marking the relevant agreement relation). The commonality of the pattern justifies seeing it as a grammatically licensed variant.

(4) a. Ainsi est donc née, il y a quatre décennies, la Ferme des corps sur laquelle un nombre

a number

considérable de recherches ont été menées $\left(2012\right.$, Google $\left.{ }^{6}\right)$

considerable of investigations have.PL been conducted

'This way, four decades ago, the Body Farm came into being, where a considerable number of investigations have been conducted'

b. In die laatste staat moet-en een groot antal schriftelijke stemm-en in that last state must-PL a great number written vote-PL worden verwerkt $(2000$, TNC)

be processed

'In that last state a great number of written votes must be processed.'

c. Esto también puede indicar que un número importante de residente-s de Florida

a number important of inhabitant-PL of Florida

están en peor situación financiera que cuatro años. $\left(2012, \mathrm{Google}^{7}\right)$

are.PL in worse situation financial than four years

'This can also indicate that an important number of inhabitants of Florida are in a worse financial situation than four years ago.'

\footnotetext{
${ }^{6}$ Quoted from http://passeurdesciences.blog.lemonde.fr/2012/01/31/des-vautours-travaillent-pour-lapolice-scientifique/, last accessed on 1 February 2012.

${ }^{7}$ Quoted from http://ecodiario.eleconomista.es/flash/, last accessed on 1 February 2012.
} 
As another illustration of hybrid syntax in a reanalysis-like setting, consider Dutch wie weet ('who knows'), which developed from an interrogative main clause introducing an indirect question, as in (5a), via a stage as parenthetical, as in (5b), into an epistemic adverb meaning 'maybe', as in (5c) (De Smet \& Van de Velde forthc.). That wie weet in (5c) is an adverb is evident from the fact that it triggers subject-verb inversion, showing that it occupies the preverbal position in a declarative main clause, and therefore can neither be a parenthetical nor itself a main clause. But even though this means $(5 c)$ is not formally a question, the clause introduced by wie weet still adopts the expectationorienting negative marker niet ('not') that is normally found in direct or indirect questions, thus preserving syntactic behaviour that belongs with the original use of wie weet as an interrogative main clause (cf. (5a)). Especially in early-twentieth-century data, the behaviour is again too common to dismiss it as an oddity of performance.

(5) a. Wie weet, of niet vergif van padden of van slangen Den jongen heb who knows if not poison of toads or of snakes the boy has verstickt, in slijm en boozen stanck $(1640$, WNT) suffocated in slime and evil stench 'Who knows, if poison of toads or snakes might not have suffocated the boy, in slime and evil stench'

b. Wie weet? hy mochte sich wenden ende berouw hebben (1637, WNT) who knows he might turn and remorse have

'Who knows? he might come round and show remorse'

c. Toen die mannen er van door gingen was de zaak hopeloos. Waren zij niet were they not gevlucht, wie weet was het niet anders afgeloopen. (1899, KBHK) fled who knows was it not differently ended 'When those men ran off the case was hopeless. If they hadn't fled, maybe it had ended differently'

In sum, then, there are at least three arguments against abruptness in reanalysis. First, the assumed abruptness of reanalysis does not explain the gradualness of actualization and, more generally, may downplay the gradience found in synchronic grammar. Second, if frequency effects offer a likely explanation for certain structural changes, particularly instances of rebracketing through fusion, it is also plausible that those changes proceed gradually, not just with gradual formal fusion but also with gradual loss of underlying compositionality. Third, the abruptness of reanalysis is contradicted by hybrid forms, which show that the behaviour of a reanalyzed item continues to be influenced by its previous uses. All three arguments point to the existence of some form of structural indecision - that is, 
they suggest that there are intermediate points between the postulated beginning and end point of syntactic reanalysis.

\subsection{Ambiguity}

The second problem area in the traditional conception of reanalysis is the role of ambiguity. The difficulty with ambiguity is that a surface element can only be ambiguous between two interpretations if those interpretations are independently supported (Fischer 1988, 2007; [AUTHOR] 2009). The form [sool] in (6) is ambiguous between the meanings 'bottom of a shoe' and 'spiritual part of man' because both those meanings are separately attested for [soul] outside the context in (6). Supposing [sool] in English meant only 'bottom of a shoe', the pun in (6) would not work, since the ambiguity with 'spiritual part of man' would simply never arise.

Truly, sir, in respect of a fine workman, I am but, as you would say, a cobbler. [...] a mender of bad soles. (Shakespeare, Julius Caesar 1.1.10-14)

The same reasoning can be applied to syntax. The reason why the sequence of a predicative adjective, for-NP and to-infinitive in (7a) is structurally ambiguous is that both of its readings are independently supported. As shown by (7b), adjectives like good can select a benefactive in the form of a for-NP, while (7c) demonstrates that for-phrases can also function as subject of a to-infinitive. From contexts like (7b-c) (and various others) it follows that the for-NP in (7a) could be the benefactive of good or the subject of the following to-infinitive. But without the contradictory evidence from (7b-c), (7a) would not be ambiguous at all. For the same kind of reasons, the German variant in (8) is unambiguous: für marks a benefactive, not an infinitival subject.

(7) a. But in general it was good for mankind to look outward to the stars. (BNC)

$\ldots \mathrm{it}_{\mathrm{i}}$ was [good for mankind] [to look outward to the stars] $]_{\mathrm{i}}$.

$\ldots \mathrm{it}_{\mathrm{i}}$ was [good] [for mankind to look outward to the stars] $]_{\mathrm{i}}$.

b. Which we believe is good for our customers. And good for our business. (BNC)

c. [a horse's] sense of smell must function for it to assess horses it has not met before (BNC)

$\begin{array}{llllllll}\text { ist es schädlich } & \text { oder } & \text { gut } & \underline{\text { fur }} & \text { einen PC } & \text { permanent } & \text { angeschaltet } & \underline{\text { zu }} \\ \text { is it harmful } & \text { or } & \text { good for } & \text { a } & \text { PC } & \text { permanently } & \text { turned-on } & \text { to } \\ \text { sein? (YCCQA) } & & & & & & & \end{array}$

be

'is it bad or good for a PC to be turned on permanently?' 
When it is accepted that a form can only be ambiguous if its conflicting interpretations already exist, it becomes problematic to treat ambiguity as a source of innovation - more likely, it is innovation that is a source of ambiguity. For instance, it is often argued that the use of for as an infinitival subject marker, as in (7c) above, arose from ambiguous contexts as in (7a), but since it is unclear how contexts like (7a) could have been ambiguous prior to the change (witness (8)), such arguments probably confuse the causes and results of change (for an alternative explanation of the development, see De Smet 2009).

Still, this line of reasoning does not completely invalidate ambiguity as a cause of change. Syntactic theory provides two solutions to make change through ambiguity a viable concept, but both fundamentally restrict the scope for genuine innovation. The first solution is to assume that language users have access to syntactic structures beyond what is attested in their specific language. Such a view has been elaborated in the claim that syntactic structures are innovated during acquisition through the workings of an innate language faculty. Guided by the language faculty, the child assigns structure to the utterances it is exposed to, homing in on a possible grammar to match its parents' linguistic output. As it makes structural choices, however, it may arrive at a grammar that differs from its parents' albeit with approximately the same output. Early formulations of this view rely on some form of Universal Grammar (e.g. Lightfoot 1979), while later versions resort to more abstract principles that guide the child in constructing its own grammar (e.g. Van Gelderen 2004). Either way, ambiguity arises during acquisition in the form of alternative choices from a preset range of options. Reanalysis occurs as such ambiguity is "newly resolved" (Anttila 1989: 197). What makes ambiguity possible in the first place is that, thanks to the innate language faculty, the set of conceivable structures is a given.

The second solution is to assume that even if language users only have access to the structures they can generalize from their linguistic experience, ambiguities can arise between attested structural possibilities. Reanalysis, if it is to result from ambiguity, can occur between such attested possibilities. For example, Fischer proposes that:

When a construction like I am going to get some water is 'reanalysed' from (9a) to (9b) [my numbering]:

(9) a. [I am going [to get some water]]

b. [I am going to [get some water]

it in fact joins another token-set. It leaves the construction-type of [V [to INF] and joins the construction-type of [Aux V]. (Fischer 2007: 145)

Changes of this type can essentially be understood in terms of analogical extension, since one construction extends its range of application into the domain of (what used to be) another, much as an 
affix can analogically extend from one root to another. De Smet (2009: 1748) labels this type of change 'categorial incursion'. In general, analogy involves the exchange of features between expressions on the basis of a (partial) similarity. Therefore, categorial incursion can be described in terms of a proportional equation, just like the more familiar instances of analogical extension. Compare, for instance, the levelling of the irregular past tense form wept and the reanalysis of rubbish from a noun to an adjective (cf. Denison 2010). The only difference between these two changes is that what is transferred is a form (-ed) in the former but an underlying structure (say, $[\ldots]_{\mathrm{AP}}$ ) in the latter.

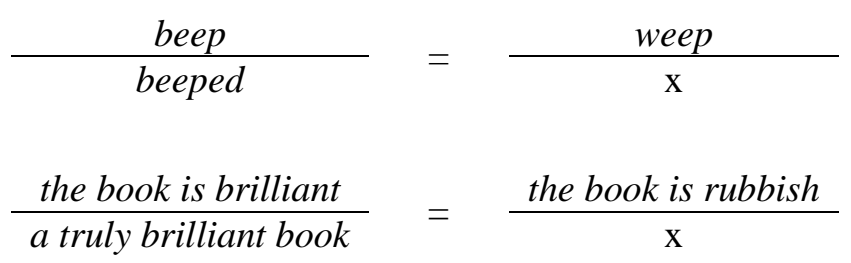

Both solutions to the ambiguity issue may raise objections. The first solution, drawing on pregiven structures, is internally consistent, but faces various empirical problems. These mostly have to do with the constraints it imposes on the form grammars may take. A language faculty is only likely to help acquisition if it can predict a limited set of structural options, but this is at odds with the wealth of cross-linguistic structural variation actually encountered (Evans \& Levinson 2009). Moreover, from the point of view of language change, models of grammar with highly restricted structural possibilities are inevitably more strongly committed to the abruptness of reanalysis and at the same time less fit to deal with the potentially non-abrupt character of change, including the gradient changes and hybrids described above (see Section 3.1; for more detailed discussion see De Smet 2009: 1730-1731).

The second solution is also likely to strike many as unsatisfactory, because it does not seem to allow for genuine innovation. The analogical character of categorial incursion seems to imply that change is nothing more than one construction extending at the expense of another. If so, all that language-internal grammatical change could bring about is an indefinite perpetuation of the same basic categories and structures, with shifting alliances but without fundamental innovation (see e.g. Harris \& Campbell 1995; Harris 2003). Skepticism about the innovative capacity of analogy is at least as old as Meillet:

l'analogie peut renouveler le détail des formes, mais laisse le plus souvent intact le plan d'ensemble du système existant ['analogy can renew details of form, but usually leaves the structure of the existing system intact'] (Meillet 1912, quoted from Traugott \& Trousdale 2010: 32)

This problem is to be addressed in the following section (Section 4). At present, suffice it to point out that the notion of categorial incursion has the advantage of not presupposing structural knowledge on the part of language users beyond what they can be expected to derive from their linguistic experience. 
In sum, it has been argued here that the role attributed to ambiguity in reanalysis is problematic or at least places more severe constraints on possible reanalyses than is commonly recognized. Specifically, no ambiguity can arise unless both relevant interpretations are somehow already licensed by the grammar.

\section{Innovation}

The foregoing discussion has shown that reanalysis, as originally conceived, does not offer a convincing account of the changes it aims to explain. The question to be addressed now is how innovation can be accounted for if not through the original model of reanalysis. The following focuses on three central elements of an alternative view on syntactic change. Such an alternative can be achieved by recognizing, first, the innovative potential of analogy; second, the existence of mechanisms of change other than reanalysis or analogy; and third, a degree of structural indeterminacy in synchronic grammar. The following addresses each point in turn, each time also highlighting a different type of change and its relevance to syntactic innovation.

\subsection{Innovation through analogy}

As pointed out above (Section 3.2), analogy has a poor reputation as a source of structural innovation. It seems that analogy can at most account for items switching categorial allegiance but not for the introduction of fundamentally new categories. However, the poor reputation is unjustified. Any analogically-licensed addition to an existing category changes that category, to the point that similarity-based generalizations can give rise to wholly new categories. Thus, over time, the piecemeal addition of new members to a category can gradually work substantial changes (De Smet 2012b). Sometimes even a single similarity-based generalization can have considerable impact on a language's grammatical system. Note here that a parallel view has been formulated for language acquisition, where it has been argued that generalizations that are new to the child can be derived by recognizing the similarities between holistically acquired chunks (Diessel \& Tomasello 2001).

As an example of the innovative power of analogy in language change, consider the collapse of the distinction between the gerund and the present participle in Old French. In Latin, the gerund is a deverbal nominalization formed by adding $-n d$ - to the verbal stem followed by an appropriate case ending, as in (10a-b). The participle is a deverbal adjective formed by adding - $n s$ to the verbal stem for the nominative singular, or -nt- with appropriate ending for other forms, as in (10c-d). As the examples show, both gerunds and present participles can be the head of non-finite clauses with their own 
arguments and adverbial modifiers (see (10b-d)), ${ }^{8}$ and both can function as adverbial clauses (see $(10 \mathrm{a}-\mathrm{c}))$. At the same time, the two clause types also differ in a number of ways. First, in the case of the gerund, the adverbial relation to the main clause is sometimes expressed by a preposition (compare $(10 \mathrm{a}-\mathrm{b}))$. Second, the two non-finite verb forms belong to different declensions. Third, the present participle, unlike the gerund but like regular adjectives, agrees in case, gender and number with a noun in the higher clause (see (10c-d)). Fourth, each clause type also has its own specific uses. For example, participles unlike gerunds can occur in a so-called Accusativus-cum-Participio construction as complement to the object of a perception verb (see (10d)).

(10)

a. Lex est recta ratio in iube-nd-o
law is right method in order-GER-ABL and forbid-GER-ABL

(quoted from Menge 2000: 738)

'The law is the right method in ordering and forbidding.'

b. Subabsurd-a dice-nd-o $[\ldots]$ risus move-ntur

Absurd-ACC.PL say-GER-ABL laugh.NOM.PL cause-PASS.PL (quoted from Menge 2000: 744)

'By saying absurdities one occasions laughter.'

c. Aquilifer pro castr-is fortissime pugna-ns

eagle-bearer.NOM.M.SG for camp-ABL very bravely fight-PP.NOM.M.SG

occiditur (quoted from Menge 2000: 715)

kill-PASS.PRES.3.SG

'The eagle-bearer, very bravely fighting for his side, is killed.'

d. Adulescent-ium greg-es Lacedaemon-e vidimus ipsi

young-man-GEN.PL band-ACC.M.PL Lacedaemon-ABL see.PERF.1.PL ourselves incredibil-i contention-e certa-nt-es

incredible-ABL exertion-ABL contend-PP-ACC.M.PL

(quoted from Menge 2000: 714)

'In Lacedaemon we have seen with our own eyes bands of young men contending with incredible exertion.'

Old French inherited this system but due to phonological changes and the reduction of inflectional endings distinctions became much less clear-cut. The gerund came down as an inflectionally

\footnotetext{
${ }^{8}$ Gerunds accompanied by their own arguments could often be replaced, sometimes obligatorily, by gerundives agreeing in case, gender and number with their semantic argument (which is at the same time their syntactic head), as in ad liberandam patriam 'to the liberation of the motherland' (lit. to the to-be-liberated.ACC.F.SG motherland.ACC.F.SG') (Menge 2000: 736-748). This alternative construction further complicated the subsequent history of the patterns involved, but for simplicity is ignored here.
} 
invariable form in -ant which, like the Latin gerund, can be preceded by a preposition, as in (11a). The present participle is a form in -ant that can agree with a noun in the higher clause, as in (11b), but the inflectional endings are seriously reduced to a choice between $\varnothing$ and $-s /-z$, depending on number, gender and case (and later just number) (Buridant 2000). Predictably, deverbal forms in -ant that function as adverbial clause and without preceding preposition are indeterminate between a participle and gerund reading wherever the participial ending is expected to be $\emptyset$, e.g. with a plural subject controller as in (11c).

(11) a. Mais il le fait por vie racat-ant (quoted from GLLF: 2225)

but he it does for life buy-back-GER

'But he does it to buy back his life.'

b. et nostre char-s mismes se repost en esperance and our body-CS.M.SG itself REFL rests in hope

attend-anz lo saluaor Ihesu Crist (quoted from Arnavielle 1997: 253)

pine-for-PP.CS.M.SG the saviour Jesus Christ

'And even our body rests in hope pining for our saviour Jesus Christ.'

c. Li autre aler-ent partout, oci-ant et pren-ant et the others went-PL everywhere kill-GER/PP and take-GER/PP and rob-ant quant qu' il ateignoi-ent (Arnavielle 1997: 255) plunder-GER/PP as much as they reach-PL

'The others went everywhere, killing and taking and plundering as much as they could lay hands on.'

Given this state of affairs, it is not very surprising to find that the distinction between gerund and present participle collapsed, with the inflectionally invariable form of the gerund invading the domain historically associated with the present participle - compare (12a), which preserves participial inflection (in line with the Latin construction in (10d) above), and (12b), which does not (GLLF: 2224).

(12) a. Et trouva ses deus chevreson-s plour-anz and found her two young-goat-CR.M.PL cry-PP.CR.M.PL (quoted from Menard 1978: 173)

'And she found her two young weeping.'

b. De toutes pars les veïst on $\underline{\text { fui-ant }}$ from all sides them.CR.M.PL could-have-seen one fleeing (quoted from Menard 1978: 172)

'They could be seen (lit. one could have seen them) fleeing from all sides.' 
We can see this development as present participles being systematically reinterpreted as gerunds (i.e. categorial incursion), or as gerunds gradually copying and taking over the distribution of present participles (i.e. analogical extension), or both. In any case, analogically-driven change seriously unsettled the system of non-finite clauses, such that the all-purpose invariable non-finite form in -ant eventually left over is, in syntactic terms, neither a real gerund nor a real participle. Analogy, then, can cause genuine innovations.

\subsection{Innovation through other mechanisms}

Apart from analogy-based changes, there are other mechanisms of change that can bring genuine innovation yet need not involve reanalysis. The role of formal and structural coalescence as a result of increasing frequency has already been discussed (see Section 3.1). Another mechanism that can be singled out here is blending. Blending involves the intertwining of parts of competing formulations (Coppock 2010: 38). As such, it is regularly involved in speech errors, as in (13).

That's torrible! (terrible/horrible) (quoted from Garrett 1980: 179).

But some instances of language change appear to be the result of a mechanism akin to blending, probably having at their basis the same processing strategies that also occasion erroneous blends (Berg 1998).

An example of syntactic blending is found in the Late Middle English examples in (14). Following verbs of believing and saying, English originally selected finite clauses introduced by the complementizer that, as in (14a). By the end of the Middle English period, however, so-called exceptional case marking (ECM) constructions appeared, possibly under Latin influence (Warner 1982). ECM constructions have a noun phrase and to-infinitive where the noun phrase appears to be assigned object case by the main verb (moving to subject position when the main verb is passivized) but thematically to function as the subject of the to-infinitive, as in (14b). Patterning with the same matrix verbs and generally spelling no or little difference in meaning (Noël 2003), the that-clauses and ECM constructions following verbs of believing and saying can be assumed to compete. In turn, this competition is a plausible source of the blended pattern illustrated in (14c), which, according to Visser, "occurs fairly frequently in the fifteenth century" (1963-1973: 2239).

(14) a. Thou bylevest that the governynge of it is nat subgit..to the folye of thise happes aventurous, but to the resoun of God. (?a1425 (c1380), MED)

'You believe that the governance of it (i.e. the world) is not subject to these accidental fortunes but to the reason of God.' 
b. His moder Olimpias knowlegede to kynge Philippe, here howsebonde, Alexander not to haue bene getten by hym. (?a1475 (?a1425), MED)

'His mother Olimpias admitted to her husband king Philippe that Alexander had not been begotten by him (lit. admitted ... Alexander not to have been begotten by him).'

c. Alle pe clerkis in pe worlde mowe not defende pat pilk tablis of moyses to teche sufficiently goddis comaundis (c1445, quoted from Visser 1963-1973: 2239)

'(Even) all the clergymen in the world could not uphold that those tables of Moses sufficiently teach (lit. to teach) God's orders.'

Although the construction in (14c) arises through recombination of parts of existing constructions, it also violates the grammatical regularities normally associated with them. That comes to introduce a non-finite clause, and a to-infinitive is additionally marked by a complementizer. It is difficult not to see this new behaviour as innovative.

\subsection{Structural indeterminacy}

While the above has shown that innovation can be achieved without reanalysis, in many cases the problem of innovation can also be approached differently. Some apparent innovations are syntactically less innovative than they may seem. This is because what counts as a syntactic innovation is partly a theoretical construct.

As indicated earlier, the need for reanalysis to a degree stems from the assumptions made by specific models of synchronic syntactic theory. When those assumptions are changed, the apparent logical necessity of reanalysis disappears. For example, the systematic application of constituency structure necessitates interpreting a variety of changes as rebracketings. But if constituent structure is thought of as variable or gradient, the same changes can be considered in a new light (see Section 3.1 above). As for syntactic innovation, changes may seem more innovative than they actually are simply because of the syntactic model used to describe them. In general, the less systematic and pervasive one holds syntactic structure to be, or the more one sees structure as epiphenomenal to function, the narrower the niche for syntax in a model of language becomes. Starting from different theoretical assumptions, many changes can be seen to give rise not so much to novel syntactic structures as to patterns that are syntactically underspecified. For instance, assuming the primacy of constructions as form-meaning pairings, abstract syntactic representations can sometimes be quite minimal (Croft 2001, 2004).

As an example, much effort has gone into determining the syntactic status of Present-day English adhortative let's as in (15) (for an overview, see De Clerck 2006: ch.5). The problem is that, distributionally, let's does not clearly pattern with any other grammatical elements. For instance, let's differs from imperatives, as it falls outside the scope of preceding don't and takes no optional subject 
you. It also differs from auxiliaries, as it allows preceding don't, takes no subject, cannot appear in tag questions and does not allow contraction with following not. In all, let's appears to defy classification, thereby also rendering pointless any attempts to establish the precise relation between let's and the following verb.

Let's face it just about everyone who can kick a ball scored against him last year! (BNC)

Communicatively, there is nothing problematic about this. To use and understand it, language users do not need to know whether let's is syntactically an imperative, an auxiliary or something else. It suffices that they recognize the conventionalized match between adhortative meaning and the sequence of clause-initial let's and a verb (cf. Croft 2004).

If we give up on trying to describe the synchronic structural status of let's (beyond noting that it is an invariable clause-initial element), this also changes how its historical development is seen. From a historical point of view, the development of let's involves fusion and dissociation from its original use as the imperative of let plus the pronoun us. This may be a gradual process, driven by increasing frequency (see Section 3.1). The development also involves functional specialization but this can be seen as a semantic change (which, incidentally, can account for the defective behaviour of let's). Beyond that, there is no reason to postulate the introduction of a wholly new syntactic structure. Where usage permits it, language users can derive generalizations, perhaps to the point of working out the purely schematic abstractions that can be said to constitute syntax. But there is no telling how far language users can or do abstract (Langacker 2000). Especially where the evidence is dubious, as in the case of let's, the syntactic structure language users assign may simply leave the problematic aspects of structure unspecified.

Croft's (2000) interpretation of reanalysis as "form-function reanalysis" is consistent with this view, highlighting the functional side of change without presupposing concomitant syntactic reorganization. Hopper's (1991) notion of "decategorialization", presented by him as one aspect of grammaticalization, likewise fits with underspecified syntax, as it implies that historical developments may lead into syntactic indeterminacy and nothing more. Unless the grammar of a language offers a template for reinterpretation (as with categorial incursion), change leads to new form-meaning pairings but not to new abstractions.

\section{Conclusions}

The previous sections have argued that the concept of syntactic reanalysis is problematic. Not only does it downplay the gradualness of change and overestimate the role of ambiguity, it may also conflate different underlying mechanisms of change as well as different types of outcomes. Moreover, the idea that syntactic reanalysis is the only way to explain grammatical innovation in language change is 
mistaken, as appears from the innovative potential of other mechanisms of change. Finally, the need for a mechanism like syntactic reanalysis is at least in part tied to models of grammar that are intolerant of syntactic indeterminacy. Acknowledging syntactic indeterminacy allows a new interpretation of various grammatical changes as functionally innovative but not necessarily syntactically innovative.

If all this argues against syntactic reanalysis as an adequate explanation of change and offers the beginning of an alternative, it still also raises several issues. First, should reanalysis be abandoned altogether? At least as a descriptive label, reanalysis may capture an important insight in language change, in that it describes a recurrent constellation of change in which functional specialization can take place without immediate surface modification. In this respect, it may continue to be a significant descriptive generalization over a range of changes. Even so, the above also suggests that explanations for changes describable as reanalyses may have to take recourse to very different underlying mechanisms, which may ultimately challenge the usefulness of even a purely descriptive application of the term.

Second, the alternatives to reanalysis suggested here are only operational to the extent that (among other things) the relative role of similarity-based generalization and structural indeterminacy in synchronic grammar is clarified. As far as grammatical change goes, the question is only beginning to be explored of how much similarity is needed for language users to spot a potential new generalization (Petré 2012). Similarly, while usage-based grammars are comfortable in principle with syntactic indeterminacy, the challenge is out for determining how much syntax is actually left (Croft 2004). With respect to the mechanisms of change discussed here, the further syntactic abstraction is found to reach, the more powerful mechanisms like categorial incursion are likely to become, whereas more restricted levels of abstraction predict a greater role for changes toward syntactic indeterminacy.

Third, the type of alternative explanations proposed here have hardly been put to the test systematically. Their application to a much wider variety of documented changes is ultimately the only way to evaluate their validity and find any shortcomings.

\section{Acknowledgements}

This paper has been made possible by the financial support from the Research Foundation Flanders. In addition, I am grateful for the comments by two anonymous referees and the participants in the workshop 'Usage-based approaches to language change', convened by Evie Coussé and Ferdinand Von Mengden in Osaka in 2011. This paper has further benefited from discussions with Graeme Trousdale in the summer of 2012. Finally, I am grateful to Stefanie Fauconnier, Catharina Peersman, Nikki van de Pol, Ildiko Van Tricht and Katrien Verveckken for their help with the examples in Latin, Spanish and Old French.

\section{Data sources}


OED Oxford English Dictionary (CD-ROM version 4.0)

PPCME2 Penn-Helsinki Parsed Corpus of Middle English (2nd edition)

MED Middle English Dictionary

COHA Corpus of Historical American English

TNC Twente Nieuws Corpus

WNT Woordenboek der Nederlandsche Taal

KBHK Koninklijke Bibliotheek Historische Kranten

BNC British National Corpus

YCCQA Yahoo-based Contrastive Corpus of Questions and Answers

\section{Glosses}

1 first person

3 third person

ABL ablative

ACC accusative

$\mathrm{CR} \quad$ cas régime ('non-subject case')

CS cas sujet ('subject case')

F feminine

GER gerund

M masculine

NOM nominative

PASS passive

PERF perfect

PRES present

PL plural

PP present participle

REFL reflexive pronoun

SG singular

\section{References}

Andersen, Henning. 1973. Abductive and deductive change. Language 49: 765-793.

Andersen, Henning. 2001. Actualization and the (uni)directionality of change. In Henning Andersen (ed.). Actualization. Linguistic change in progress. Amsterdam: John Benjamins. 225-248.

Anttila, Raimo. 1989. Historical and comparative linguistics. Amsterdam: John Benjamins. 
Arnavielle, Teddy. 1997. Le morphème -ant: unité et diversité. Étude historique et théorique. Leuven: Peeters.

Barlow, Michael and Suzanne Kemmer (eds.). Usage-based models of language. Stanford: CSLI..

Berg, Thomas. 1998. Linguistic structure and change. An explanation from language processing. Oxford: Clarendon Press.

Brems, Lieselotte. 2003. Measure Noun constructions. An instance of semantically-driven grammaticalization. International Journal of Corpus Linguistics 8: 283-312.

Buridant, Claude. 2000. Grammaire nouvelle de l'ancien français. Paris: SEDES.

Bybee, Joan. 2004. Mechanisms of change in grammaticalization. The role of frequency. In Brian D. Joseph (ed.). The handbook of historical linguistics. Oxford: Blackwell. 602-623.

Bybee, Joan L. 2006. From usage to grammar. The mind's response to repetition. Language 82: 711733.

Bybee, Joan. 2010. Language, usage and cognition. Cambridge: Cambridge University Press.

Bybee, Joan and John L. McClelland. 2005. Alternatives to the combinatorial paradigm of linguistic theory based on domain general principles of human cognition. The Linguistic Review 22: 381410.

Campbell, Lyle. 2001. What's wrong with grammaticalization? Language Sciences 23: 113-161.

Coppock, Elizabeth. 2010. Parallel grammatical encoding in sentence production. Evidence from syntactic blends. Language and Cognitive Processes 25: 38-49.

Croft, William. 2000. Explaining language change. An evolutionary approach. London: Longmann.

Croft, William. 2001. Radical construction grammar. Syntactic theory in typological perspective. Oxford: Oxford University Press.

Croft, William. 2004. Logical and typological arguments for Radical Construction Grammar. In Mirjam Fried and Jan-Ola Östman (eds.). Construction grammar(s). Cognitive and cross-language dimensions. Amsterdam: John Benjamins. 273-314.

Croft, William and D. Alan Cruse. 2004. Cognitive Linguistics. Cambridge: Cambridge University Press.

De Clerck, Bernard. 2006. The imperative in English. A corpus-based, pragmatic analysis. Unpublished doctoral dissertation, University of Ghent.

Denison, David. 2010. Category change in English with and without structural change. In Elizabeth C. Traugott and Graeme Trousdale (eds.). Gradience, gradualness and grammaticalization. Amsterdam: John Benjamins. 105-128.

De Smet, Hendrik. 2009. Analysing reanalysis. Lingua 119: 1728-1755.

De Smet, Hendrik. 2012a. The course of actualization. Language 88: 601-633.

De Smet, Hendrik .2012b. Spreading patterns. Diffusional change in the English system of complementation. Oxford: Oxford University Press. 
De Smet, Hendrik and Freek Van de Velde. Forthcoming. Serving two masters. Form-function friction in syntactic amalgams. Studies in Language.

Diessel, Holger and Michael Tomasello. 2001. The acquisition of finite complement clauses in English: A corpus-based analysis. Cognitive Linguistics 12: 1-45.

Evans, Nicholas and Stephen C. Levinson. 2009. The myth of language universals. Language diversity and its importance for cognitive science. Behavioral and Brain Sciences 32: 429-492.

Fischer, Olga. 1988. The Rise of the for NP to V Construction. An Explanation. In Graham Nixon and John Honey (eds). An historic tongue. Studies in English linguistics in memory of Barbara Strang. London: Routledge. 67-88.

Fischer, Olga. 2000. Grammaticalisation: unidirectional, non-reversible? The case of to before the infinitive in English. In Olga Fischer, Anette Rosenbach and Dieter Stein (eds). Pathways of change. Grammaticalization in English. Amsterdam: John Benjamins. 149-169.

Fischer, Olga. 2007. Morphosyntactic change. Functional and formal perspectives. Oxford: Oxford University Press.

Garrett, Merril F. 1980. Levels of processing in sentence production. In B. Butterworth (ed.). Language production. Vol. 1. Speech and talk. London: Academic Press. 177-220.

GLLF = Grand Larousse de la langue française. 1986. Paris: Larousse.

Goldberg, Adele E. 2006. Constructions at work. The nature of generalization in language. Oxford: Oxford University Press.

Harris, Alice C. 2003. Cross-linguistic perspectives on syntactic change. In Brian D. Joseph and Richard D. Janda (eds). The handbook of historical linguistics. Oxford: Blackwell. 529-551.

Harris, Alice C. and Lyle Campbell. 1995. Historical syntax in cross-linguistic perspective. Cambridge: Cambridge University Press.

Haspelmath, Martin. 1998. Does grammaticalization need reanalysis? Studies in Language 22: 315351.

Haspelmath, Martin. 1999. Optimality and diachronic adaptation. Zeitschrift für Sprachwissenschaft 18: 180-205.

Hay, Jennifer B. and R. Harald Baayen. 2005. Shifting paradigms. Gradient structure in morphology. Trends in Cognitive Sciences 9: 342-348.

Heine, Bernd, Ulrike Claudi and Friederike Hünnemeyer. 1991. Grammaticalization. A conceptual framework. Chicago: University of Chicago Press.

Hopper, Paul. 1991. On some principles of grammaticization. In Elizabeth C. Traugott and Bernd Heine (eds). Approaches to grammaticalization. Vol. 2. Focus on types of grammatical markers. Amsterdam: John Benjamins. 17-35.

Hopper, Paul and Elizabeth C. Traugott. 2003. Grammaticalization. Cambridge: Cambridge University Press. 
Joseph, Brian D. 1992. Diachronic explanation. Putting speakers back into the picture. In Garry W. Davis and Gregory K. Iverson (eds). Explanation in historical linguistics. Amsterdam: John Benjamins. 123-144.

Joseph, Brian. 2004. Rescuing traditional (historical) linguistics from grammaticalization theory. In Olga Fischer, Muriel Norde and Harry Perridon (ed.). Up and down the cline - the nature of grammaticalization. Amsterdam: John Benjamins. 45-72.

Keller, Rudi. 1990. Sprachwandel von der unsichtbaren Hand in der Sprache. Tübingen: Francke.

Kortmann, Bernd and Ekkehard König. 1992. Categorial reanalysis. The case of deverbal prepositions. Linguistics 30: 671-697.

Kroch, Anthony. 1989. Function and grammar in the history of English. Periphrastic do. In Ralph W. Fasold and Deborah Schiffrin (eds.). Language change and variation. Amsterdam: John Benjamins. 134-169.

Krug, Manfred. 2003. Frequency as a determinant in grammatical variation and change. In Günter Rohdenburg and Britta Mondorf (eds). Determinants of grammatical variation in English. Berlin: Mouton de Gruyter. 7-67.

Langacker, Ronald W. 1977. Syntactic Reanalysis. In Charles N. Li (ed.). Mechanisms of syntactic change. Austin: University of Texas Press. 57-139.

Langacker, Ronald W. 1987. Foundations of cognitive grammar. Vol. 1. Theoretical prerequisites. Stanford: Stanford University Press.

Langacker, Ronald W. 2000. A dynamic usage-based model. In Michael Barlow and Suzanne Kemmer (eds). Usage-based models of language. Stanford: CSLI. 1-63.

Lightfoot, David W. 1979. Principles of diachronic syntax. Cambridge: Cambridge University Press.

Menard, Philippe. 1978. Manuel du français du moyen âge. Vol. 1. Syntaxe de l'ancien français. Bordeaux: SOBODI.

Menge, Hermann. 2000. Lehrbuch der lateinische Syntax und Semantik. Darmstadt: Wissenschaftliche Buchgesellschaft.

Newmeyer, Frederick J. 1998. Language form and language function. Cambridge, MA: MIT Press.

Noël, Dirk. 2003. Is there semantics in all syntax? The case of accusative and infinitive constructions vs. that-clauses. In Günther Rohdenburg and Britta Mondorf (eds). Determinants of grammatical variation in English. Berlin: Mouton de Gruyter. 329-345.

Petré, Peter. 2012. General productivity: How become waxed and wax became a copula. Cognitive Linguistics 23: 27-65.

Plank, Frans. 2004. Inevitable reanalysis. From local adpositions to approximative adnumerals, in German and wherever. Studies in Language 28: 165-201.

Roberts, Ian. 2007. Diachronic syntax. Oxford: Oxford University Press.

Timberlake, Alan. 1977. Reanalysis and actualization in syntactic change. In Charles N. Li (ed.). Mechanisms of syntactic change. Austin: University of Texas Press. 141-177. 
Traugott, Elizabeth C. 2008. The grammaticalization of NP of NP patterns. In Alexander Bergs and Gabriele Diewald (eds.). Constructions and language change. Berlin: Mouton de Gruyter. 23-45. Traugott, Elizabeth C. and Graeme Trousdale. 2010. Gradience, gradualness and grammaticalization. In Elizabeth C. Traugott and Graeme Trousdale (eds.). Gradience, gradualness and grammaticalization. Amsterdam: John Benjamins. 19-44.

Van Gelderen, Elly. 2004. Grammaticalization as economy. Amsterdam: John Benjamins.

Verveckken, Katrien. 2012. Towards a constructional account of high and low frequency binominal quantifiers in Spanish. Cognitive Linguistics 23: 421-478.

Visser, Frederikus Theodorus. 1963-1973. An historical syntax of the English language. Leiden: Brill.

Warner, Anthony. 1982. Complementation in Middle English and the methodology of historical syntax. A study of the Wiclifite sermons. London: Croom Helm. 